\title{
Experimental demonstration of floral allocation costs in Crepis tectorum
}

\author{
Stefan Andersson
}

\begin{abstract}
Information on floral resource costs is fundamental for understanding how selection operates on floral morphology. In this study, I explored the cost of maturing flowers in a self-incompatible population of the ligulate composite Crepis tectorum L. by experimentally manipulating floral investment and then monitoring the response in reproductive effort. Plants on which the heads were removed during the initial stage of ligule expansion had a higher reproductive effort than plants whose heads were removed immediately after flower maturation, and the latter plants had a higher reproductive effort than plants on which all flowers were permitted to set fruit. Judging from biomass estimates and the magnitude of the observed tradeoffs, the amount of resources allocated to maturing flowers was about half as great as the amount of resources devoted to fruit maturation. These and other results suggest that floral tradeoffs may exert negative selection on floral size variables.
\end{abstract}

Key words: floral evolution, Crepis tectorum, reproduction, resource allocation, tradeoff.

Résumé : L’information sur les coûts de la ressource florale est fondamentale pour comprendre comment la sélection agit sur la morphologie florale. Dans cette étude, l'auteur examine le coût de la maturation des fleurs chez une population auto-compatible de la composée ligulée Crepis tectorum L., en manipulant expérimentalement l'investissement floral, avant de suivre la réaction de l'effort de reproduction. Les plantes sur lesquelles les fleurs ont été enlevées au cours des stades initiaux de l'expansion des ligules montrent un effort de reproduction plus important que les plants dont les fleurs ont été enlevées immédiatement après leur maturation, et ces derniers plants montrent un effort de reproduction plus grand que ceux sur lesquelles on a permis à toutes les fleurs de former des fruits. À partir de biomasses estimées et de l'importance des compromis observés, la quantité de ressource allouée à la maturation des fleurs est environ la moitié de la quantité de ressource allouée à la maturation des fruits. Ces résultats, et d'autres, suggèrent que les compromis floraux peuvent exercer une sélection négative sur les variables des dimensions florales.

Mots clés : évolution florale, Crepis tectorum, reproduction, allocation des ressources, compromis.

[Traduit par la Rédaction]

\section{Introduction}

Although plant-pollinator interactions represent the principal force driving evolutionary change in floral morphology (Grant 1949; Stebbins 1970), there is a great potential for ecological forces other than pollinators, such as tradeoffs, flower enemies (nectar thieves, seed predators, fungal pathogens, etc.), and various abiotic factors, to determine the optimum floral phenotype of a species or population (Galen 1999; Galen et al. 1999). For example, there is abundant evidence that seed predators preferentially attack plants with large, conspicuous flowers (Brody 1992; Kudoh and Whigham 1998) and that substantial biomass may be invested in floral structures (Waller 1979; Lovett-Doust and Cavers 1982; Ashman 1994b; Galen et al. 1999). Hence, the optimum flower size should be a compromise between pollinator-mediated selection for larger displays (Bell 1985) and negative selection imposed by flower enemies and tradeoffs with fruit and seed production. For floral tradeoffs to impose

Received 27 September 2005. Published on the NRC Research Press Web site at http://canjbot.nrc.ca on 26 July 2006.

S. Andersson. ${ }^{1}$ Plant Ecology and Systematics, Department of Ecology, University of Lund, Sölvegatan 37, S-223 62 Lund, Sweden.

${ }^{1}$ Corresponding author (e-mail: stefan.andersson@ekol.lu.se). selection on flower size, increased expenditure of resources on pollinator attraction must entail reduced allocation to other activities. A straightforward way of testing for such "opportunity costs" (sensu Gulmon and Mooney 1986) is to manipulate investment in floral structures and then evaluate allocation to subsequently produced flowers, fruits, and seeds (Pyke 1991; Ashman and Schoen 1997; Andersson 1999, 2000, 2001, 2005; see also Ashman and Schoen 1996).

Flower morphology is often associated with variation in breeding system, with selfing lineages having smaller and less attractive flowers than their outbreeding relatives (Ornduff 1969). Such reductions have long been attributed to selection for minimizing expenditure on attractive floral structures as plants become less dependent on outcrossing (Charlesworth and Charlesworth 1987; Lloyd 1987), but other mechanisms have also been implicated in this process, for example, selection for small flower size to increase rates of self-pollen deposition (Robertson and Lloyd 1991) and correlated responses to reductions in nonfloral features (Primack 1987; Andersson 1997). While much attention has focused on factors that could promote the shift from outcrossing to autogamy (e.g., Baker 1955; Darwin 1876; Lloyd 1979; Lande and Schemske 1985), there are still too few empirical data to draw general conclusions about the relative importance of resource costs and other mechanisms 
in driving evolutionary reductions in floral morphology. In this regard, it seems particularly relevant to explore floral tradeoffs in species that show correlated variation in mating system and floral size variables.

Populations of Crepis tectorum L. (Asteraceae), an annual, monocarpic plant whose basic attraction units are inflorescence (heads) rather than single flowers, have undergone considerable divergence in mating system and floral morphology. In particular, the more or less self-incompatible plants growing on outcrops on the Baltic island of Öland (C. tectorum subsp. pumila (Liljebl.) Sterner) have larger flowers and thus more conspicuous heads than the more autogamous outcrop plants in surrounding regions (Andersson 1989, 1996a). Patterns of correlation provide no evidence to suggest that flowers are costly to produce in this species (Andersson 1996a), possibly because these costs are mitigated by resource resorption from senescing corollas and (or) photosynthesis of the protective bracts (phyllaries) that surround each head (cf. Bazzaz et al. 1979; Ashman $1994 a$ ). Hence, it is still unclear whether tradeoffs contribute to the association between small flower size and autogamy seen in the comparative analyses. In the present study, I performed a resource-manipulation experiment with plants of C. tectorum to explore the relationship between floral investment and subsequent flower and fruit production, the relative costs of flower versus fruit maturation, and the role of phyllaries in mitigating the reproductive costs in this species.

\section{Material and methods}

\section{Study system}

Crepis tectorum consists of a geographically widespread weed ecotype (Eurasia, North America) and a series of morphologically distinct forms adapted to rock outcrops in NW Eurasia. Plants of $C$. tectorum generally germinate in the autumn, persist as leaf rosettes during the winter, and flower in the following summer. Flowering is determinate, starting with the head terminating the main shoot and ending with heads on the lowermost branches. Each head consists of a variable number of ligulate, hermaphroditic, protandrous flowers that develop into one-seeded, indehiscent fruits dispersed by the wind. Flowering of a head is centripetal, starting at the margin and progressing inwards. A 4-5 d long "ligule expansion stage" (during which the individual flowers expand their ligules and become sexually mature) is followed by a "maintenance stage" (during which the flowers remain sexually functional). Finally, all the ligules, their attached anther filaments, and the styles absciss more or less simultaneously. The phyllaries remain green after flower senescence, regardless of the fraction of flowers that mature into fruits (S. Andersson, personal observations).

The plant material in this study originated from a natural population ca. $15 \mathrm{~km} \mathrm{~S}$ of Vickleby on the Baltic island of Öland (SE Sweden). Plants from this locality belong to C. tectorum subsp. pumila, an early-flowering form adapted to the calcareous grasslands ("alvars") characterizing parts of this island. Flowering in this habitat generally occurs in May and early June before the summer drought when the soil quickly dries because of high insolation. In rainy summers, flowering plants can be found throughout the summer. Individual plants vary greatly in head number (range 1-30), but only one or two heads per branch are in bloom at any given time. Flowers of this taxon are self-incompatible and thus require insect visitation (mainly members of Diptera and Hymenoptera) to set fruit, contrasting with the more or less autogamous flowers normally found in this species (Andersson 1988, 1989). Because of pollination-induced flower senescence, the maintenance stage for subsp. pumila ranges from 1-2 d for heads that are pollinated at the onset of female receptivity (i.e., immediately after the ligule expansion stage) to 4-5 d for heads that remain unpollinated (S. Andersson, personal observations).

\section{Resource-manipulation experiment}

In February 2005, I sowed a bulked sample of fruits (obtained by mixing fruits from the terminal head on each of 50 open-pollinated maternal plants) on moist filter paper in Petri dishes. About 150 of the resulting seedlings were planted in $300 \mathrm{~cm}^{3}$ plastic pots with peat soil and placed in random positions on a bench in an unheated, insect-free greenhouse. When the first plants reached anthesis (early May), I assigned each plant to one of four treatments: (1) removal of (immature) heads at the end of the bud stage or during the onset of ligule expansion (bud-removal group), (2) removal of heads after ligule expansion (flower-maturation group), (3) stimulation of fruit production by hand pollination (fruit-maturation group), and (4) no manipulation (control group). Hand pollinations were carried out by rubbing one or two heads, each from a different pollen donor, onto the recipient head at the onset of female receptivity. Experimental procedures were repeated every day or every second day, until all plants had ceased to initiate new heads (late June). When plants began to senesce (mid-June), I hand pollinated two "assay-heads" (marked at the late bud stage) on each individual to provide data on late resource status (see below). Water was supplied daily or as needed, but no extra fertilizer was applied. A total of 148 plants were used in the experiment.

At the onset of fruit maturation, I identified two control plants that appeared to be self-compatible. The estimated fruit set of these plants, based on a bulked sample of five heads per plant, was $83 \%$ and $87 \%$, respectively. Since these values approached the mean fruit set of the hand-pollinated plants (see Results), I re-assigned these individuals to the fruit-maturation group.

To test for treatment effects on reproductive effort, I scored each individual for the number of the heads that developed to the flower stage (including the removals) and used the assay-heads to estimate the number of fruits per head, the fruit biomass per head (dry mass) and fruit mass (fruit biomass divided by fruit number). Data from different assay-heads were averaged to provide a single data point for each individual. Head number and assay-head variables are expressed late in the ontogeny and are therefore expected to be affected by (early) investments in flower and fruit development — and by experimental manipulations that mitigate or strengthen these tradeoffs. Head number and fruit number per head contribute directly to individual fecundity, and fruit size is positively correlated with germination rate under natural conditions (Andersson 1996b). The 
presence of two hand-pollinated assay-heads on each plant was assumed to have a minor effect on the number of heads produced. All plants were dead at the final harvest (early July).

Following the detection of significant treatment effects (see below), I quantified the cost of floral maturation as the difference in reproductive effort between the bud-removal group and the flower-maturation group, and the cost of fruit maturation as the difference between the flower-maturation group and the fruit-maturation group. These comparisons involved the original response variables as well as "overall reproductive effort", estimated as the product of head number, fruit number per head, and fruit mass. The role of phyllaries as a source for assimilates during flower and fruit maturation was assessed by comparing the reproductive effort of the unpollinated control plants (whose phyllaries remained until senescence) with plants on which all heads (including the phyllaries) had been removed during the bud or flowering stage. Note that the floral costs refer to resources invested during the ligule expansion stage and that no attempt was made to estimate costs associated with bud development.

\section{Biomass measurements}

To estimate the amount of biomass allocated to flowers during the ligule expansion stage, I collected one removed head from each of 20 individuals in the bud-removal group, and obtained a corresponding sample of heads from the flower-maturation group. Each head was scored for floral biomass, recorded to the nearest $0.1 \mathrm{mg}$ after removing all nonfloral structures (phyllaries, etc.) and drying at room temperature. The biomass allocated to flowers during the ligule expansion stage was then estimated as the difference in mean biomass between the two treatment groups. These data were compared with the biomass allocated to flowers during the fruit stage, estimated as the dry mass of all fruit tissue (including unfertilized ovaries) in one head on each of 20 plants in the fruit-maturation group. For comparative purposes, I also determined the biomass of fruits and ovaries in each of 20 heads from the control group (each from a separate plant).

\section{Data analyses}

Differences between different treatment groups were tested for significance using one-way analyses of variance (ANOVA). Analyses involving more than two groups were combined with post hoc tests (Tukey's method) to determine which pair(s) of treatment means were significantly different. Residuals of all ANOVAs approached normality, so no transformations were necessary. All means are presented with their standard errors (SE).

\section{Results}

\section{Biomass and percent fruit set}

Plants in the flower-maturation group allocated almost twice as much biomass to floral tissue (mean $=26.3 \mathrm{mg}$ per head, $\mathrm{SE}=0.77, n=20$ ) as plants in the bud-removal group (mean $=13.5 \mathrm{mg}$ per head, $\mathrm{SE}=0.58, n=20$ ), a highly significant difference $\left(F_{[1,38]}=175.37, P<0.001\right.$, one-way ANOVA).

The mean fruit set of plants in the fruit-maturation cate-
Table 1. Results of one-way ANOVA for each of the response variables in the resource-manipulation experiment with Crepis tectorum.

\begin{tabular}{|c|c|c|c|c|}
\hline $\begin{array}{l}\text { Variable or } \\
\text { source of varia- } \\
\text { tion }\end{array}$ & df & MS & $F$ & $P$ \\
\hline \multicolumn{5}{|l|}{ No. of heads* } \\
\hline Treatment & 3 & 14685.96 & 85.10 & $<0.001$ \\
\hline Error & 144 & 172.58 & & \\
\hline \multicolumn{5}{|c|}{ Fruit number per head $*, \dagger$} \\
\hline Treatment & 3 & 264.63 & 1.04 & 0.378 \\
\hline Error & 144 & 255.07 & & \\
\hline \multicolumn{5}{|c|}{ Fruit biomass per head (mg) ${ }^{*}, \dagger$} \\
\hline Treatment & 3 & $1.10 \times 10^{-4}$ & 3.92 & 0.010 \\
\hline Error & 144 & $2.80 \times 10^{-5}$ & & \\
\hline \multicolumn{5}{|c|}{ Fruit mass $(\mathrm{mg})^{\dagger}$} \\
\hline Treatment & 3 & $7.18 \times 10^{-8}$ & 16.75 & $<0.001$ \\
\hline Error & 136 & $4.28 \times 10^{-9}$ & & \\
\hline
\end{tabular}

gory was $81 \%$ (range $=45 \%-95 \%, n=20)$, whereas few fruits were produced by heads on the control plants (mean $=2 \%$, range $=0 \%-10 \%, n=20)$. On average, the hand-pollinated heads allocated $27.6 \mathrm{mg}$ biomass to fruits and unfertilized ovaries ( $\mathrm{SE}=0.83 \mathrm{mg}, n=20$ ), i.e., almost twice as much as the biomass allocated to flowers during the ligule expansion stage $(26.3-13.5=12.8 \mathrm{mg}$ per head $)$. Heads on control plants allocated $4.7 \mathrm{mg}$ biomass to fruit and (or) ovary tissue $(\mathrm{SE}=0.40 \mathrm{mg}, n=20$ ).

\section{Reproductive effort}

One-way ANOVAs demonstrated significant treatment effects for head number, fruit biomass per head, and fruit mass, whereas differences in fruit number per head failed to reach significance (Table 1). Judging from the treatment means and the post hoc tests (Table 2), the bud-removal plants produced $25 \%$ more heads than plants in the flowermaturation category, whereas fruit number, fruit biomass, and fruit mass showed nonsignificant differences between these categories. Compared with plants in the flower-maturation group, the fruit-maturation plants produced $34 \%$ fewer heads and $14 \%$ lighter fruits (Table 1). The measure of overall reproductive effort was $20 \%$ lower in the flowermaturation group (794 $\mathrm{mg}$ ) than in the bud-removal group $(995 \mathrm{mg}$ ), and 36\% lower in the fruit-maturation group $(506 \mathrm{mg})$ than in the flower-maturation group $(794 \mathrm{mg})$.

The unpollinated controls (with intact phyllaries) allocated more biomass to fruits than plants whose heads (and phyllaries) were removed (Table 2). Regarding head number, the mean for the controls was higher than the mean for the flower-maturation group, but lower than the mean for the bud-removal group.

\section{Discussion}

Floral allocation costs are likely to play a crucial role in 
Table 2. Treatment means (SE in parentheses) for each of the response variables in the resource-manipulation experiment with Crepis tectorum.

\begin{tabular}{lllll}
\hline Response variable & Bud removal & Flower maturation & Fruit maturation & Control \\
\hline No. heads* & $97.6 \mathrm{a}(2.63)$ & $78.1 \mathrm{c}(2.22)$ & $51.3 \mathrm{~d}(1.29)$ & $85.5 \mathrm{~b}(2.35)$ \\
Fruit number per head $*, \dagger$ & $28.8 \mathrm{a}(2.84)$ & $29.4 \mathrm{a}(2.40)$ & $33.0 \mathrm{a}(2.28)$ & $34.3 \mathrm{a}(2.98)$ \\
Fruit biomass per head $(\mathrm{mg}) * \dagger$ & $9.76 \mathrm{~b}(0.097)$ & $9.80 \mathrm{~b}(0.075)$ & $9.68 \mathrm{~b}(0.068)$ & $13.25 \mathrm{a}(0.106)$ \\
Fruit mass $(\mathrm{mg})+*$ & $0.354 \mathrm{~b}(0.012)$ & $0.346 \mathrm{~b}(0.011)$ & $0.299 \mathrm{c}(0.009)$ & $0.409 \mathrm{a}(0.012)$ \\
\hline
\end{tabular}

Note: Values followed by different letters are significantly different at $P<0.05$ (Tukey's test).

${ }^{*} N=35-39$ plants per treatment.

"Based on data from two "assay-heads".

${ }^{\star} N=33-38$ plants per treatment.

the evolution of floral morphology, particularly in relation to changes in breeding system (Charlesworth and Charlesworth 1987; Lloyd 1987) and adaptation to stressful growth conditions (Galen 1999; Galen et al. 1999). Despite the broad significance of such costs, there have been relatively few efforts to establish a causal link between floral investment and allocation of resources to other plant functions (Pyke 1991; Ashman and Schoen 1997; Andersson 1999, 2000, 2001, 2005). In this study, I explored the floral costs of C. tectorum by subjecting plants to various resource-manipulation treatments and then testing for compensatory responses in flower and fruit production. Next, I evaluate the results with particular emphasis on the hypothesis that floral tradeoffs reduce the optimum flower size and thus contribute to the association between small flower size and autofertility in this species (Andersson 1989, 1996a).

Consistent with the experimental results from other wild plant species (Andersson 1999, 2000, 2005), maturing flowers of C. tectorum subsp. pumila were found to represent a significant sink for assimilates: plants whose heads were removed immediately before or during the onset of ligule expansion produced significantly more heads than plants whose heads were removed after the maturation stage. The early head removal treatment had no detectable effect on the number and biomass of fruits in the hand-pollinated assay-heads, indicating that (late) fruits represented relatively "weak" sinks for resources that became available after the immature heads were removed. One possibility is that immature heads and maturing fruits utilize different pools of resources, thereby reducing the amount of resources that can be reallocated between flower and fruit maturation. Nevertheless, fruit production seems to put a great drain on a plant's resources, as evidenced by the unusually low head number and fruit mass of plants in the fruit-maturation category.

Judging from the biomass measurements, fruit maturation was twice as "expensive" as flower maturation: the biomass invested in ligules, anthers, and styles during the ligule expansion phase was about half as great as the biomass devoted to fruits and unfertilized ovaries in the fruitmaturation group. This difference is consistent with the magnitude of treatment effects in the resource-manipulation experiment: stimulating fruit maturation caused a larger decline in both head number and fruit mass than permitting heads to mature their flowers. In fact, the reduction in overall reproductive effort attributable to fruit and flower maturation was $36 \%$ and $20 \%$, respectively, approaching the relative costs inferred from the biomass measurements. That data on biomass sometimes give a qualitatively good impression of the amount of resources that can be allocated to other functions has also been observed in other systems: a recent investigation of Nigella sativa (Ranunculaceae) revealed a relatively close agreement between the amount of "saved" biomass after early perianth removal and the compensatory increase in the amount of biomass allocated to seeds in the removal group (Andersson 2005).

The unpollinated control plants had a significantly higher reproductive effort than plants in the two head removal groups, presumably because the phyllaries contributed resources to flower and fruit development, similar to observations of other studies (Bazzaz et al. 1979; Galen et al. 1993; Herrera 2005). However, the amount of resources supplied by the phyllaries was probably too low to mitigate the costs of flower and fruit production. First, reducing the floral costs by removing heads before the onset of ligule expansion caused a larger increase in final head number than leaving the phyllaries intact (relative to the flower-maturation group). Second, the positive effect of the phyllaries was too weak to balance the reduction in head number and fruit mass associated with fruit maturation.

Floral allocation costs include not only resources allocated to maturing corollas, stamens, and pistils, but also the resources invested in the secretion of nectar, maintenance respiration, and transpiration by fully developed flowers (Pyke 1991; Ashman and Schoen 1997). Such "maintenance costs" probably made a minor contribution to the floral costs observed in this study. First, all head removals occurred before the maintenance stage, and most hand pollinations shortened the maintenance stage by inducing flower senescence (S. Andersson, personal observations). Second, the maintenance costs were too low to prevent the phyllaries from acting as a source for assimilates in the control group, despite the unusually long maintenance stage of the unpollinated heads in this category $(4-5 \mathrm{~d} ; \mathrm{S}$. Andersson, personal observations).

Results of this investigation confirm previous observations (Andersson 1989) that plants of C. tectorum subsp. pumila are dependent on insect visitation to set fruit. Consistent with the inferred advantage of large, attractive structures under these circumstances (Bell 1985; Galen 1999), this taxon has larger flowers and wider heads than autogamous forms of $C$. tectorum, particularly when differences in plant stature and other size characters are accounted for (Andersson 1989). In view of these findings and the results of this study, I hypothesize that flower size is under stabilizing selection, the optimum phenotype being a compromise 
between pollinator-mediated selection for larger floral displays and tradeoffs with head production. In this context, it is worth noting that plants of subsp. pumila have a greater ability to reallocate unused resources to new heads in years when soil moisture is high throughout the season than in years when the flowering period is shortened by a severe summer drought (Andersson 1988); hence, selection for small flowers should be most efficient in relatively wet years.

For tradeoffs to constrain evolutionary change, they must be manifested as negative genetic correlations between variables (Reznick 1985). Regarding genetic correlations involving flower size, available data indicate considerable heterogeneity, with estimates ranging from negative (Mossop et al. 1994; Robertson et al. 1994; Campbell 1997) to nonsignificant or positive (Conner and Via 1993; Eckhart 1993; Andersson 1996d; Worley and Barrett 2000). This disparity is perhaps not surprising given the diversity of species and variables involved, but may also result from the failure to detect tradeoffs in some studies. In the case of C. tectorum, measures of floral size have been found to show positive correlations with head number (Andersson 1996a), contrasting with the tradeoff between flower maturation and head number in this study. I have no explanation for this discrepancy; however, it is possible that genetically based tradeoffs were confounded by positive covariance generated by differences in resource status (van Noordwijk and de Jong 1986; Worley and Barrett 2003) or by factors related to the use of hybrid genotypes in some of the correlation analyses (Andersson 1996a).

Floral allocation costs are just one of several factors that could impose negative selection on flower size. Populations of $C$. tectorum adapted to outcrops have undergone considerable reduction in plant stature and fruit size compared with weed populations (Andersson 1989, 1996a), and experimental data from a pumila population indicate that selection still favours a reduction in these characters (Andersson $1996 b, 1996 c)$. Given these observations and the detection of positive genetic correlations between plant height, fruit size, and floral size characters (Andersson 1993), there is a great opportunity for selective forces other than tradeoffs to impose negative selection on flower size and facilitate evolutionary reductions in flower size if plants become less dependent on outcrossing. A similar scenario - involving both resource costs and "size correlations" — has also been invoked to explain the floral reduction in the Nigella arvensis complex (Andersson 1997, 2000).

\section{Acknowledgements}

The author thanks Erik Norell and Bengt Jacobsson for technical assistance in the greenhouse, and Honor C. Prentice for linguistic advice. Financial support was provided by the Swedish Natural Science Council.

\section{References}

Andersson, S. 1988. Limiting factors on seed production in Crepis tectorum ssp. pumila. Acta Phytogeogr. Suec. 76: 9-20.

Andersson, S. 1989. The evolution of self-fertility in Crepis tectorum (Asteraceae). Plant Syst. Evol. 168: 227-236. doi:10. 1007/BF00936101.

Andersson, S. 1993. Population differentiation in Crepis tectorum
(Asteraceae): patterns of correlation among characters. Biol. J. Linn. Soc. 49: 185-194. doi:10.1006/bijl.1993.1029.

Andersson, S. 1996a. Floral reduction in Crepis tectorum (Asteraceae): tradeoffs and dominance relationships. Biol. J. Linn. Soc. 57: 59-68. doi:10.1006/bijl.1995.0005.

Andersson, S. 1996b. Seed size as a determinant of germination rate in Crepis tectorum (Asteraceae): evidence from a seed burial experiment. Can. J. Bot. 74: 568-572.

Andersson, S. 1996c. Phenotypic selection on plant height in a segregating hybrid population of Crepis tectorum (Asteraceae). Int. J. Plant Sci. 157: 488-492. doi:10.1086/297366.

Andersson, S. 1996d. Floral variation in Saxifraga granulata: phenotypic selection, quantitative genetics and predicted response to selection. Heredity, 77: 217-223.

Andersson, S. 1997. Genetic constraints on phenotypic evolution in Nigella (Ranunculaceae). Biol. J. Linn. Soc. 62: 519-532. doi:10.1006/bijl.1997.0174.

Andersson, S. 1999. The cost of floral attractants in Achillea ptarmica (Asteraceae): Evidence from a ray removal experiment. Plant Biol. 1: 569-572.

Andersson, S. 2000. The cost of flowers in Nigella degenii inferred from flower and perianth removal experiments. Int. J. Plant Sci. 161: 903-908. doi:10.1086/317558.

Andersson, S. 2001. Fitness consequences of floral variation in $\mathrm{Se}$ necio jacobaea (Asteraceae): evidence from a segregating hybrid population and a resource manipulation experiment. Biol. J. Linn. Soc. 74: 17-24. doi:10.1006/bij1.2001.0559.

Andersson, S. 2005. Floral costs in Nigella sativa (Ranunculaceae): Compensatory responses to perianth removal. Am. J. Bot. 92: 279-283.

Ashman, T.L. 1994a. A dynamic perspective on the physiological cost of reproduction in plants. Am. Nat. 144: 300-316. doi:10. 1086/285676.

Ashman, T.L. 1994b. Reproductive allocation in hermaphrodite and female plants of Sidalcea oregana ssp. spicata (Malvaceae) using four currencies. Am. J. Bot. 81: 433-438.

Ashman, T.L., and Schoen, D.J. 1996. Floral longevity: fitness consequences and resource costs. In Floral biology. Edited by D.G. Lloyd and S.C.H. Barrett. Chapman and Hall, New York, USA. pp. 112-139.

Ashman, T.L., and Schoen, D.J. 1997. The cost of floral longevity in Clarkia tembloriensis: An experimental investigation. Evol. Ecol. 11: 289-300. doi:10.1023/A:1018416403530.

Baker, H.G. 1955. Self-compatibility and establishment after "long-distance" dispersal. Evolution, 9: 347-348. doi:10.2307/ 2405656.

Bazzaz, F.A., Carlson, R.W., and Harper, J.L. 1979. Contribution to reproductive effort by photosynthesis of flowers and fruits. Nature, 279: 554-555. doi:10.1038/279554a0.

Bell, G. 1985. On the function of flowers. Proc. R. Soc. Lond. B. Biol. Sci. 224: 223-265.

Brody, A.K. 1992. Oviposition choices by a predispersal seed predator (Hylemya sp.). I. Correspondence with hummingbird pollinators and the role of plant size, density and floral morphology. Oecologia, 91: 56-62.

Campbell, D.R. 1997. Genetic and environmental variation in lifehistory traits of a monocarpic perennial: a decade-long field experiment. Evolution, 51: 373-382. doi:10.2307/2411109.

Charlesworth, D., and Charlesworth, B. 1987. The effect of investment in attractive structures on allocation to male and female functions in plants. Evolution, 41: 948-968. doi:10.2307/ 2409184.

Conner, J., and Via, S. 1993. Patterns of phenotypic and genetic correlation among morphological and life-history traits in wild 
radish, Raphanus raphanistrum. Evolution, 47: 704-711. doi:10. 2307/2410086.

Darwin, C. 1876. The effects of cross- and self-fertilization in the vegetable kingdom. John Murray, London, UK.

Eckhart, V.M. 1993. Do hermaphrodites of gynodioecious Phacelia linearis (Hydrophyllaceae) trade off seed production to attract pollinators? Biol. J. Linn. Soc. 50: 47-63. doi:10.1006/bijl. 1993.1047.

Galen, C. 1999. Why do flowers vary? The functional ecology of variation in flower size and form within natural plant populations. Bioscience, 49: 631-640. doi:10.2307/1313439.

Galen, C., Dawson, T.E., and Stanton, M.L. 1993. Carpels as leaves: meeting the carbon cost of reproduction in an alpine buttercup. Oecologia, 95: 187-193. doi:10.1007/BF00323489.

Galen, C., Sherry, R.A., and Carroll, A.B. 1999. Are flowers physiological sinks or faucets? Costs and correlates of water use by flowers of Polemonium viscosum. Oecologia, 118: 461-470. doi: $10.1007 / \mathrm{s} 004420050749$.

Grant, V. 1949. Pollination system as isolating mechanisms in angiosperms. Evolution, 3: 82-97. doi:10.2307/2405454.

Gulmon, S.L., and Mooney, H.A. 1986. Costs of defence and their effects on plant productivity. In On the economy of plant form and function. Edited by T.J. Givnish. Cambridge University Press, London, UK. pp. 681-698.

Herrera, C.H. 2005. Post-floral perianth functionality: contribution of persistent sepals to seed development in Helleborus foetidus (Ranunculaceae). Am. J. Bot. 92: 1486-1491.

Kudoh, H., and Whigham, D.F. 1998. The effect of petal size manipulation on pollinator/seed predator mediated female reproductive success of Hibiscus moscheutos. Oecologia, 117: 70-79. doi:10.1007/s004420050633.

Lande, R., and Schemske, D.W. 1985. The evolution of self-fertilization and inbreeding depression in plants. I. Genetic models. Evolution, 39: 24-40. doi:10.2307/2408514.

Lloyd, D.G. 1979. Some reproductive factors affecting the selection of self-fertilization in plants. Am. Nat. 113: 67-79. doi:10.1086/ 283365 .
Lloyd, D.G. 1987. Allocations to pollen, seeds and pollination mechanisms in self-fertilizing plants. Funct. Ecol. 1: 83-89.

Lovett-Doust, J., and Cavers, P.B. 1982. Biomass allocation in hermaphrodite flowers. Can. J. Bot. 60: 2530-2534.

Mossop, R., Macnair, M.R., and Robertson, A.W. 1994. Within-population variation in sexual resource allocation in Mimulus guttatus. Funct. Ecol. 8: 410-418.

Ornduff, R. 1969. Reproductive biology in relation to systematics. Taxon, 18: 121-133. doi:10.2307/1218671.

Primack, R.B. 1987. Relationships among flowers, fruits and seeds. Annu. Rev. Ecol. Syst. 18: 409-430. doi:10.1146/annurev.es.18. 110187.002205.

Pyke, G.H. 1991. What does it cost a plant to produce floral nectar? Nature, 350: 58-59. doi:10.1038/350058a0.

Reznick, D.N. 1985. Cost of reproduction: an evaluation of the empirical evidence. Oikos, 44: 257-267.

Robertson, A.W., and Lloyd, D.G. 1991. Herkogamy, dichogamy and self-pollination in six species of Myosotis (Boraginaceae). Evol. Trends Plant. 5: 53-63.

Robertson, A.W., Diaz, A., and Macnair, M.R. 1994. The quantitative genetics of floral characters in Mimulus guttatus. Heredity, 72: $300-311$.

Stebbins, G.L. 1970. Adaptive radiation of reproductive characteristics in angiosperms. Annu. Rev. Ecol. Syst. 1: 307-326. doi:10.1146/annurev.es.01.110170.001515.

van Noordwijk, A.J., and de Jong, G. 1986. Acquisition and allocation of resources: their influence on variation in life history tactics. Am. Nat. 128: 137-142. doi:10.1086/284547.

Waller, D.M. 1979. The relative costs of self- and cross-fertilized seeds in Impatiens capensis (Balsaminaceae). Am. J. Bot. 66: 313-320.

Worley, A.C., and Barrett, S.C.H. 2000. Evolution of floral display in Eichhornia paniculata (Pontederiaceae): genetic correlations between flower size and number. J. Evol. Biol. 14: 469-481.

Worley, A.C., and Barrett, S.C.H. 2003. Consequences of hierarchical allocation for the evolution of life-history traits. Am. Nat. 161: 153-167. doi:10.1086/345461. PMID: 12650469. 